\title{
PESQUISA QUALITATIVA: ESTUDANDO COMO AS COISAS FUNCIONAM
}

\author{
QUALITATIVE RESEARCH: STUDYING HOW THINGS WORK
}

\section{INVESTIGACIÓN CUALITATIVA: ESTUDIANDO CÓMO FUNCIONAN LAS COSAS}

\author{
Luciana de Oliveira Souza Mendonça ${ }^{1}$ \\ https://orcid.org/0000-0002-8950-092X \\ Isabel Maria Sabino de Farias ${ }^{2}$ \\ https://orcid.org/0000-0003-1799-0963
}

\footnotetext{
${ }^{1}$ Instituto Federal de Educação, Ciência e Tecnologia do Ceará, Maracanaú, Ceará - Brasil. E-mail: professoralucianamendonca@gmail.com.

${ }^{2}$ Universidade Estadual do Ceará, Fortaleza, Ceará - Brasil. E-mail: isabel.sabino@uece.br.
}

Robert Edward Stake é um dos pesquisadores americanos mais renomados por suas contribuições teóricas acerca de temas relacionados com a investigação científica, em particular as pesquisas qualitativas. Por sua produção acadêmica em torno do assunto recebeu, em 1998, o prêmio Lazarfeld, da American Evaluation Association. Além disso, recebeu o título de doutor honorário em 1994 pela Universidade de Uppsala, na Suécia, e, em 2009, pela Universidade Valladolid, na Espanha. Em 2007 foi homenageado pela American Educational Research Association por sua considerável produção em pesquisas educacionais, principalmente as que enfocam estudos das experiências em sala de aula, as interpretações pessoais e os processos e contextos institucionais, geralmente na forma de estudo de casos.

O livro de sua autoria Pesquisa Qualitativa: estudando como as coisas funcionam é considerado um clássico na pesquisa educacional e objetiva contribuir para a reflexão sobre como planejar e realizar uma pesquisa qualitativa. Nessa direção, a obra instiga o leitor a pensar sobre as várias etapas dessa abordagem investigativa, considerando que o conhecimento acerca de um fenômeno educacional é processual, produzido em um tempo determinado, com atores e em cenários diversos, que se engendra, funciona e se modifica num contexto específico. Nesse 
processo, o pesquisador é o intérprete que produz os dados e os analisa com base em suas referências e experiências, buscando detalhar de maneira holística o funcionamento de um fenômeno, com profundidade, explicitando sua singularidade e complexidade por meio de diversos olhares, na busca de evidências.

Esse livro destina-se a alunos de graduação e pós-graduação, professores e pesquisadores que buscam compreender e aprender a planejar um estudo qualitativo não apenas de forma teórica, mas mediante contato com exemplos detalhados de pesquisas realizadas que, em sua maioria, adotaram estudos de caso. Além disso, outro diferencial da obra é a apresentação de um roteiro didático para a compreensão de cada capítulo, com passos que contemplam questões que ajudam o leitor a refletir sobre como desenvolver todas as etapas de uma investigação qualitativa.

$\mathrm{O}$ autor partilha com o leitor suas experiências em pesquisas educacionais de abordagem qualitativa com o uso de estudos de caso com objetivo de fazê-lo refletir sobre a importância de desenvolver um olhar apurado para observar as pessoas e o contexto em que estão inseridas, evitando estereótipos, na busca de evidências tecidas por meio da triangulação de fontes que contribuam para relacionar as diferentes informações, suas convergências, divergências e complementações na construção e interpretação crítica do que se observa, de como se observa e de que perspectiva se observa, considerando as experiências e a interpretação do próprio pesquisador.

A obra está organizada em 12 capítulos, cujos assuntos contemplam desde a concepção e reflexão sobre a pesquisa qualitativa, o papel do pesquisador como instrumento e intérprete, a importância da experiência do pesquisador no desenvolvimento dentro dessa perspectiva, até a abordagem de aspectos práticos, como o estabelecimento e a formulação de uma questão de pesquisa, a seleção de métodos de coleta de dados, a interpretação e análise dos resultados na busca de evidências por meio da triangulação e produção do relatório final, considerando a ética no seu desenvolvimento, de forma a permitir ao leitor compreender todas etapas da investigação na abordagem qualitativa, sobretudo nas pesquisas que recorrem a estudos de caso.

No primeiro capítulo, os temas centrais abordam a essência, os métodos e os pontos fracos que existem em diferentes tipos de pesquisas qualitativas. Cada pesquisa realizada depende do método e de como o pesquisador conduz o estudo. Essencialmente, esses estudos buscam, em maior ou menor nível: a interpretação mediante a captação dos significados dos sujeitos; a valorização das experiências, enfocando as observações, considerando o 
subjetivismo dos sujeitos e do próprio pesquisador; e a caracterização de cada contexto, com suas particularidades, como processos mutáveis, sendo mais holísticos e humanísticos, levando em conta a singularidade dos sujeitos e dos objetos, honrando a diversidade e buscando na ética a redução dos riscos.

Nesses termos, a epistemologia dos pesquisadores qualitativos é definida por Stake como essencialmente construtivista, uma vez que o conhecimento é resultante da interação entre os seres humanos e o mundo. O significado da realidade é constituído nessa interação social e, por conseguinte, não é neutro, entendendo-se que a dicotomia subjetivo-objetivo ou sujeitoobjeto não se mantém. O construcionismo se dirige para o mundo da intersubjetividade construído na interação social, compartilhado para a geração de conhecimento e de seus significados de forma coletiva por meio dos processos sociais.

O autor finaliza o capítulo enfatizando que há uma forte ligação entre a pesquisa qualitativa e a experiência pessoal, os aprendizados particular e situacional, o conhecimento profissional e a microanálise; que as ligações, na pesquisa qualitativa, entre o conhecimento científico e coletivo, com a generalização e a microanálise, podem ser fracas ou fortes e que, embora as pesquisas qualitativas e quantitativas tenham suas diferenças, podem, de alguma forma, se complementar e estabelecer conexões.

Nos segundo e terceiro capítulos, os temas centrais tratam do papel do pesquisador como instrumento e intérprete que considera a sua experiência e a dos sujeitos como importantes ferramentas para a compreensão dos fenômenos investigados. Parte-se do pressuposto de que toda pesquisa qualitativa passa pela interpretação e pela experiência do pesquisador, dos sujeitos da pesquisa e dos leitores dos relatórios e artigos de pesquisa.

Interpretar é, também, compor uma narrativa ou história sobre e a partir de suas experiências; entretanto, a composição vai além de reconhecer a relação entre a interpretação e a importância da experiência. Compor uma pesquisa qualitativa parte do estabelecimento dessa relação por meio das descrições selecionadas pelo pesquisador com algumas relações conceituais, tornando essa composição mais consistente em busca de evidências, sem perder de vista a crítica, tecida com esteio em um certo ceticismo e, ao mesmo tempo, do reconhecimento do pesquisador como intérprete das diferentes interpretações a partir das diferentes experiências dos sujeitos que compõem e participam da pesquisa.

Nesse contexto, o papel do pesquisador qualitativo é compreender o fenômeno estudado e retratar a realidade de forma holística, buscando se aproximar ao máximo da compreensão da 
realidade investigada em sua complexidade, sendo o principal instrumento de interpretação e de coleta de dados. Além disso, o pesquisador qualitativo deve compor com profundidade a realidade interpretada e vivenciada ao reconhecer que as experiências que as pessoas vivem são dinâmicas e plurais e cuja complexidade do objeto em estudo pode ser compreendida a partir da triangulação das diferentes interpretações das múltiplas visões e/ou realidades, valorizando, de forma empática e respeitosa, as experiências dos indivíduos estudados e também sua própria experiência, preservando os princípios da ética de pesquisa e resguardando dos riscos os envolvidos, tanto pela maneira de agir durante o estudo até a produção do texto da pesquisa.

Do quarto ao sexto capítulo são abordados aspectos práticos da pesquisa qualitativa, que vão desde a formulação de uma questão de pesquisa até a seleção de métodos de coleta de dados.

O autor enfatiza que o primeiro passo para entender como as coisas funcionam é determinar quais são as questões importantes que revelam a singularidade, particularidade, contexto, relevância e complexidade do problema a ser investigado para planejar e conduzir o estudo e, finalmente, organizar o relatório final. Salienta também a importância, durante esse processo, da realização de uma boa revisão de literatura utilizando bibliografias atualizadas. Esclarece que, a partir da definição do objeto de estudo, o pesquisador precisa buscar a coerência entre o método e os procedimentos de coleta de dados, que são guiados pelas questões de pesquisa, buscando certa originalidade mediante diferentes conexões e interpretações que possam aprofundar a temática investigada. Lembra que a escolha dos procedimentos de coleta de dados deve ser guiada e apresentar coerência com o objetivo do estudo, levando-se em consideração os possíveis informantes, o contexto, o tempo para pesquisa, o número de participantes e os procedimentos a serem triangulados. Entre as estratégias de coleta de dados mais usuais na investigação qualitativa, Stake destaca a observação, a entrevista, as questões expositivas, os questionários e o uso de diários para o registro de dados.

O autor traz para a discussão que o pesquisador qualitativo deve desenvolver a habilidade de elaborar os instrumentos para observar, entrevistar, registrar e aplicar um questionário com questões objetivas ou situações expositivas com o objetivo de compreender o processo que está sendo investigado. Para tanto, deve apurar o olhar para ver além do visível, ouvir até os silêncios, as pausas, fazer descrições objetivas, para tentar produzir o máximo de dados possível para compreender o processo. O pesquisador deve também realizar a triangulação entre o objeto de estudo, a revisão de literatura, o referencial teórico e 
metodológico e os dados empíricos construídos para fundamentar uma análise consistente e coerente, evidenciando um olhar holístico que busque compreender o fenômeno em sua complexidade e profundidade, como "um sistema em funcionamento" que busque compreender como as coisas funcionam.

Do sétimo ao décimo capítulo, os temas centrais estão relacionados com a busca de evidências, por meio da triangulação, da verificação das informações com os envolvidos, da contribuição de outros pesquisadores e da autoavaliação para uma apreciação crítica, durante o processo de pesquisa, da construção da análise e síntese dos dados.

A evidência, na pesquisa qualitativa, é a busca de uma forma de sustentar o conhecimento que é produzido por meio da coerência, da lógica e a da relação entre os dados coletados, selecionados, analisados e triangulados, com consistência tanto empírica quanto teórica, que proporciona ao pesquisador maior convicção de que o problema da investigação foi respondido e possibilita a outros intérpretes a compreensão de como a pesquisa foi realizada e como os resultados obtidos respondem aos objetivos da pesquisa.

Os pesquisadores triangulam suas evidências para obterem a compreensão e a convicção de como as coisas funcionam, diz Robert Stake. Para tanto, coletam e analisam os dados a partir de um processo que envolve a seleção de sujeitos como importantes informantes, a observação de diferentes eventos e contextos, a identificação e a relação de categorias empíricas para a compreensão do objeto. Durante e após a etapa de coleta dos dados, o pesquisador deve organizá-los de forma orgânica e relacional, realizando a separação e a reunião de fragmentos essenciais para uma síntese que permita uma microanálise ou uma macroanálise, ou a relação entre ambas, para a compreensão de como o objeto de estudo funciona a partir dos dados coletados e triangulados.

Para Stake, a triangulação não necessariamente é uma forma de validação ou confirmação, pois, quando se respeitam as diferentes experiências, interpretações e pontos de vista obtidos por diferentes sujeitos e instrumentos de coleta de dados, percebe-se que a triangulação pode ser uma forma de diferenciação em que tanto a convergência quanto a divergência são consideradas importantes e complementares para a compreensão do que se investiga. Além disso, em muitos casos, a triangulação ajuda o pesquisador a compreender a complexidade daquilo que está investigando.

O autor também destaca a possibilidade de se melhorar o grau de evidência apresentando-se anotações ou versões preliminares para as pessoas que forneceram as 
informações para que elas façam revisões ou comentários para evitar enganos e complementar os dados. Deve-se, entretanto, ter o cuidado para não expor outras pessoas envolvidas no processo e atentar-se aos cuidados éticos na proteção dos sujeitos. Sugere o autor, ainda, que haja mais pesquisadores no campo para cruzar diferentes olhares sobre o mesmo fenômeno e, também, diferentes pessoas para interpretar as informações e ler os relatórios ou dados preliminares para melhorar as evidências. Essa prática, que envolve a revisão dos dados mediante a interação e a crítica de outros olhares durante o processo de pesquisa, é denominada pelo autor de painéis de revisão. Além disso, Stake defende que, durante todo processo investigativo, o pesquisador faça uma autoavaliação de como e do que está pesquisando, e como está intervindo na realidade e no contexto investigado. Esse processo é denominado de pesquisa-ação, com o estudo da própria ação do pesquisador no ato de pesquisar.

Nos capítulos 11 e 12, são discutidos a elaboração do relatório final e os aspectos éticos da pesquisa qualitativa. Um bom relatório de pesquisa baseia-se na reflexão dialética de todo o processo de investigação e na capacidade do pesquisador de realizar uma síntese interativa, relacionando a experiência do trabalho com a questão de pesquisa, objetivando compreender o processo em sua totalidade e reconhecendo as fragilidades do trabalho, bem como as fortalezas que podem apontar caminhos para novas compreensões complexas e integradas. Os relatórios de pesquisas qualitativas utilizam descrições detalhadas dos contextos, eventos observados, fontes dos dados e fases da pesquisa, estabelecendo relações entre o objeto de estudo e as múltiplas realidades e interpretações elaboradas.

No decurso da elaboração do relatório, há sempre um processo dialético que revela as contradições, o processo de diálogo entre as seguintes dualidades: pesquisa qualitativa e pesquisa quantitativa; macrointerpretação e microinterpretação; o conhecimento geral e o particular; o conhecimento científico e o profissional; o conhecimento coletivo e o individual; dados agregativos e dados interpretativos; medições de dados quantitativos e compreensão experiencial; realidade única e múltiplas realidades; análise e síntese; particularização e generalização.

Stake chama atenção também para o fato de que, muitas vezes, as críticas sobre as pesquisas qualitativas estão relacionadas com a generalização e o grau de replicação dos resultados das pesquisas realizadas em diferentes contextos, a validação externa da pesquisa, a valorização das interpretações dos sujeitos em detrimento da realidade objetiva e o excesso de descrições e relatos, que poderiam comprometer a validade interna da pesquisa e, 
consequentemente, o "rigor científico". Por outro lado, lembra Stake, critica-se a pesquisa quantitativa realizada numa perspectiva positivista por nem sempre ser capaz de captar e mensurar a complexidade e as peculiaridades dos fenômenos sociais e educacionais, uma vez que as realidades social e educacional podem não se enquadrar em padrões preestabelecidos, assim como as interações entre os sujeitos-objetos-contextos não devem ser desconsiderados. A crítica também recai sobre a validade da pesquisa que é baseada em explicações causais, na busca da objetividade, livre de valores e interpretações. Nesse sentido, adverte que diferentes problemas de pesquisa podem ser abordados sobre diferentes pontos de vista, utilizando diferentes tipos de pesquisa; por isso a importância de definir o problema antes da escolha do tipo de abordagem e o método de pesquisa. Antes da escolha de qualquer um deles, o pesquisador deve refletir sobre "o que", "quem", "onde", "como", "por quê" e em qual perspectiva o problema deve ser analisado.

Para o autor é preciso superar a comparação ou a rivalidade entre a relevância da pesquisa quantitativa em detrimento da pesquisa qualitativa, ou vice-versa, porque as críticas baseiam-se em diferentes conceitos, de diversas perspectivas. No seu entendimento, é necessário conhecer as distintas abordagens, métodos, perspectivas teórico-metodológicas para realizar a melhor escolha para fazer uma pesquisa capaz de responder aos objetivos a que se propõe. Pensando nessa direção, é importante também considerar que determinados problemas de investigação podem ser abordados utilizando-se não apenas uma abordagem quantitativa ou qualitativa, mas uma pesquisa de abordagem mista que triangule diferentes métodos e tipos de dados, na busca de melhorar a compreensão do objeto de estudo em sua complexidade.

Considera-se que o livro de Robert Stake é um convite para uma reflexão, cheio de exemplos e de descobertas, de forma dialógica e didática, destinado a alunos, professores e pesquisadores interessados em compreender como a pesquisa qualitativa funciona na prática, em suas especificidades, complexidade e profundidade, na busca de compreendê-la em sua totalidade.

\section{Referências}

STAKE, R. E. Pesquisa Qualitativa: estudando como as coisas funcionam. Porto Alegre: Penso, 2011.

Recebido em: 12/11/2019

Aprovado em: 12/02/2020

Publicado em: 28/08/2020 